\title{
Significant technical advances in broadband seismic stations in the Lesser Antilles
}

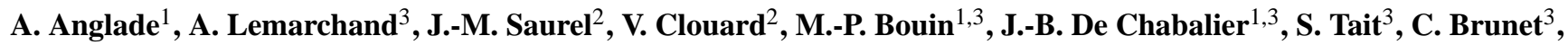

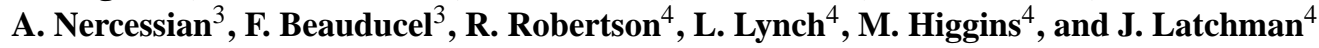 \\ ${ }^{1}$ Observatoire Volcanologique et Sismologique de Guadeloupe (OVSG/IPGP), Le Houëlmont \\ 97113 Gourbeyre, Guadeloupe, French West Indies \\ ${ }^{2}$ Observatoire Volcanologique et Sismologique de Martinique (OVSM/IPGP), Morne des Cadets, \\ 97250 Fonds Saint Denis, Martinique, French West Indies \\ ${ }^{3}$ Institut de Physique du Globe de Paris (IPGP), Paris, France \\ ${ }^{4}$ Seismic Research Centre (SRC/UWI), St. Augustine, Trinidad and Tobago, West Indies
}

Correspondence to: A. Lemarchand (arnaudl@ipgp.fr)

Received: 22 October 2014 - Revised: 13 February 2015 - Accepted: 3 March 2015 - Published: 10 April 2015

\begin{abstract}
In the last few years, French West Indies observatories from the Institut de Physique du Globe de Paris (IPGP), in collaboration with The UWI Seismic Research Centre (SRC, University of West Indies), have modernized the Lesser Antilles Arc seismic and deformation monitoring network. 15 new, permanent stations have been installed that strengthen and expand its detection capabilities. The global network of the IPGP-SRC consortium is now composed of 20 modernized stations, all equipped with broadband seismometers, strong motion sensors, Global Positioning System (GPS) sensors and satellite communication for real-time data transfer. To enhance the sensitivity and reduce ambient noise, special efforts were made to improve the design of the seismic vault and the original Stuttgart shielding of the broadband seismometers ( 240 and 120 s corner period). Tests were conducted for several months, involving different types of countermeasures, to achieve the highest performance level of the seismometers. GPS data, realtime and validated seismic data (only broadband) are now available from the IPGP data centre (http://centrededonnees.ipgp. fr/index.php?\&lang=EN). This upgraded network feeds the Caribbean Tsunami Warning System supported by UNESCO and establishes a monitoring tool that produces high quality data for studying subduction and volcanic processes in the Lesser Antilles arc.
\end{abstract}

\section{Introduction}

Following the submarine earthquake of Sumatra on 26 December 2004 and the subsequent devastating tsunami, UNESCO has been orchestrating activities and immediate action to establish a tsunami and other coastal hazards Early Warning System (EWS) in the Caribbean and Adjacent Regions. The immediate response included the establishment of an Interim Tsunami Advisory Information Service to the Caribbean Sea and Adjacent Regions through the Pacific Tsunami Warning Center in Hawaii. Meanwhile, since 2005, the Intergovernmental Oceanographic Commission of UNESCO (IOCUNESCO) has coordinated Intergovernmental Coordination Group (ICG) discussions and working groups to address all kinds of issues with a view to establish a fully functional Tsunami Warning System in the Caribbean Region (ICG/CARIBE EWS). In this context, existing seismic network operators of the Caribbean countries have been meeting in regular technical workshops for many years to agree the specifications of seismic monitoring stations that contribute to the Tsunami Warning System.

Two major thrust earthquakes killed several hundred people and destroyed cities during historical times: the 1843 $M 8.5$ earthquake and the $1839 M 8.0$ earthquake (e.g., Bernard and Lambert, 1988; Shepherd, 1992; Feuillet et al., 2011; Hough, 2013). In 1843, evidence of tsunamis was reported in Antigua and Nevis, and the oldest earthquake known also triggered a tsunami in 1690 as the sea withdrew over a distance of $200 \mathrm{~m}$ at Charleston in Nevis (Lan- 
der et al., 1997). Nowadays, the high level of coastal development/tourist infrastructure is critical to the economies of the Caribbean islands states which are vulnerable to several major telluric hazards such as landslides, volcanic eruptions, and especially earthquakes and tsunamis. Observing, understanding and monitoring these hazards can help mitigate their impact. Indeed, comparison of damage caused by the recent massive earthquakes and tsunamis that shook the subduction zones of Sumatra ( $M=9.3$, 2004; e.g. Singh et al., 2011) and Japan ( $M=9.1,2011$; e.g. Mori et al., 2011), reveals a difference of approximately one order of magnitude in the scale of the loss of life, mostly attributable to disparate observational capacity, levels of scientific understanding and preparedness in the two regions.

The Lesser Antilles subduction zone spans over $1000 \mathrm{~km}$ from Trinidad to the Virgin Island and the regional seismicity has been recorded and processed since the mid-1950's by the SRC (http://www.uwiseismic.com), based in Trinidad and Tobago and since 1980, by the two French IPGP West Indies Volcanological and Seismological Observatories (OVS), located in Martinique and Guadeloupe. Those centres were originally dedicated to volcano monitoring, and used to operate local networks producing their own earthquake solutions for events in the vicinity of French islands, but even though they have been contributing with arrivals from regional events to the SRC since 1953, recording the seismicity of the Lesser Antilles arc was not the main goal. Most of the stations in operation since the beginning of the seismologic observations in the Lesser Antilles have been short-period, vertical component seismic sensors, with analog telemetry.

In 2006 and 2007, KNMI (Koninklijk Nederlands Meteorologicsh Institut), USGS (United States Geological Survey) and SRC committed themselves to update their seismic networks with digital broadband stations (Fig. 1) and real-time communications to meet the tsunami warning requirements. However, these modernized stations, while greatly improving regional monitoring capability, did not cover the whole Antilles arc (French West Indies and Grenada Islands). Hence around 2008, IPGP began modernization of Guadeloupe and Martinique seismic networks, in collaboration with the Seismic Research Centre (University of West Indies-Trinidad) and initiated data sharing in real-time via satellite communications (VSAT). In 2010, IPGP and SRC had the opportunity to further fill gaps in the geometry of the seismic network of the Antilles arc with four additional stations installed in Cariaccou (Grenada), Saint-Lucia, Dominica and Antigua, but also to strengthen the network by adding several radomes, notably providing protection from severe weather. Moreover IPGP and SRC paved the way to a new strategy regarding the installation of regional seismic broadband stations to achieve high scientific standards regarding data quality. Thus best practice in observational seismology (Trnkoczy et al., 2011; Forbriger, 2012) and GPS networks (Sakic, 2013; UNAVCO) has been implemented to achieve performance goals and special care was taken in the construction of the seismic vault

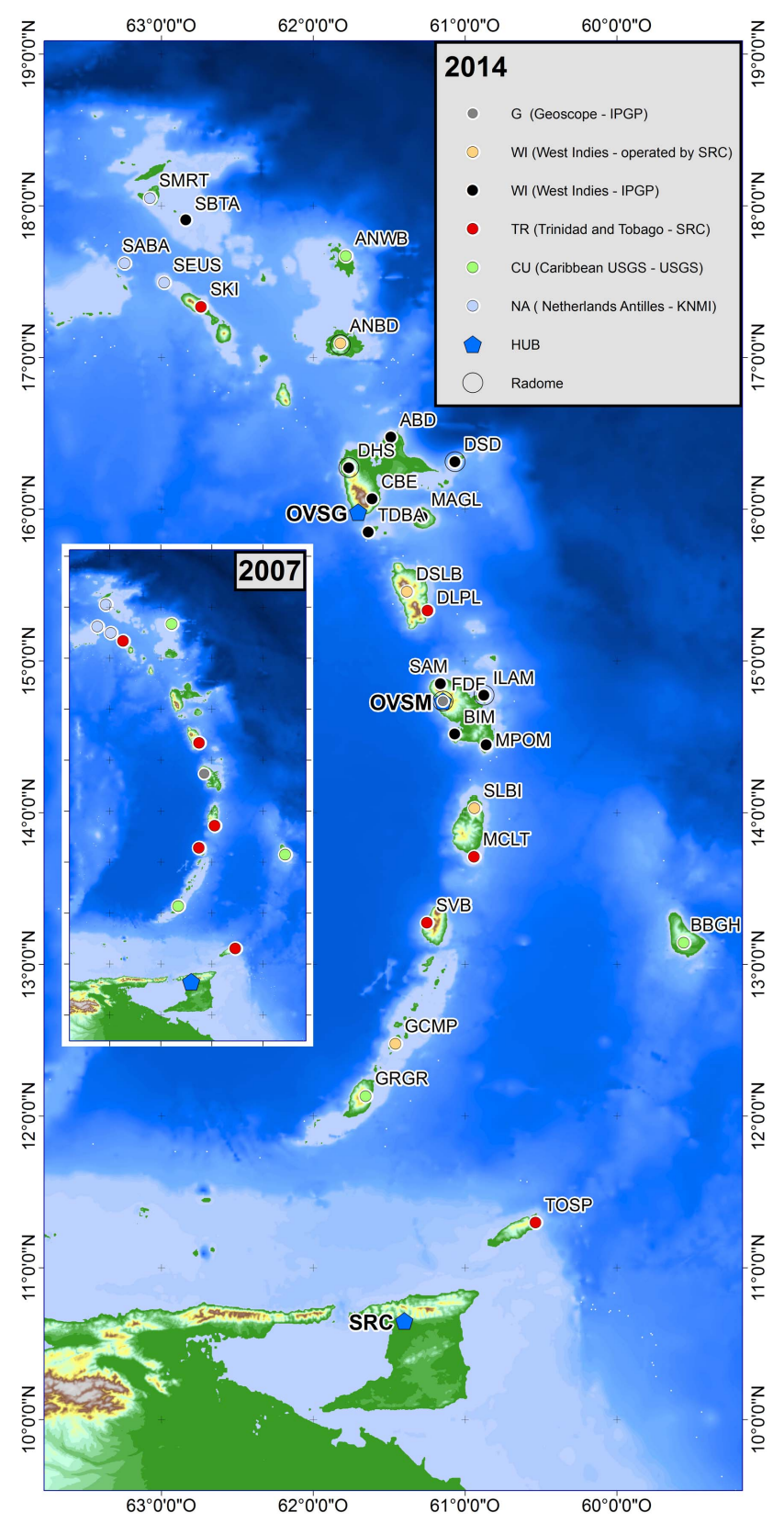

Figure 1. Digital broadband seismic stations in the Lesser Antilles in 2007 and 2014, from IPGP (France, WI and G), KNMI (Netherlands, NA), USGS (United States of America, CU) and SRC (Trinidad and Tobago, TR and WI).

and sensor shielding with systematic tests carried out. Finally, SRC and the two French West Indies observatories designed, installed and now jointly operate an arc scale seismic network in Lesser Antilles. This paper, describes: (i) the station distribution within the context of existing regional networks and the design strategy of the network, (ii) the global characteristics of stations, (iii) strategies used to improve data quality, (iv) results achieved with this network. 


\section{The WI network}

The WI network was installed by SRC and IPGP between 2008 and 2014. It is composed of stations geographically distributed all along the Lesser Antilles subduction zone, from Grenadine islands in the south, to St Barthélémy in the north (Fig. 1), and from Eastern Guadeloupe in the west to La Désirade in the east. Together with the other networks (CU, NA, G and TR), the WI stations complete the coverage of the subduction zone. The Caribbean is subject to hurricanes, earthquakes and volcanic events, therefore, measures were employed to promote system robustness and reliability; damage to any one component does not lead to complete network failure. Data are collected in real-time by three VSAT hubs located in Guadeloupe, Martinique and Trinidad, at the OVSG/IPGP, the OVSM/IPGP and at the SRC respectively. The VSAT technology allows us to share the data without the use of any terrestrial link or Internet access, both of which are vulnerable in case of natural disasters. The system is designed to send data from any one station to the three hubs. Such redundancy promotes data recovery, in the event of failure of up to two of the three hubs. We chose to cover four stations and one hub with a radome that can resist winds of up to $300 \mathrm{kph}$, thus protecting a minimal network for early warning and strong earthquake detection with winds up to $210 \mathrm{kph}$. Those stations are: (a) ANBD in Antigua in the northern part of the arc, where most of the hurricanes go, (b) DSD in La Désirade and (c) DHS in Deshaies, which form the largest possible east-west line in the arc, (d) and ILAM in la Caravelle which is the closest land to the subduction zone. There is now at least one broadband station in each major island of the arc and along an east-west line where the islands arc is the broadest, making the subduction zone well instrumented and allowing large-scale studies of the processes at work and the output of enhanced data products (e.g. focal mechanisms, source characterization). Because of the particular elongated shape of the islands along the arc, this network can also be viewed as a large seismometer antennae for global studies.

\section{Station design}

The stations all share the following features: (1) very Small Aperture Terminal (VSAT) satellite telemetry, (2) solar power and 10-days battery autonomy to ensure high reliability, (3) multi sensors stations with broadband seismometer, accelerometer and continuous GPS, (4) vault and installation design to minimize environmental effects on the instruments (Fig. 2). They share with the TR network the same VSAT satellite telemetry and they have the same kind of solar power source.

In order to sample the whole range of expected tectonic movements in a subduction region: from very-long term slow movements to strong high frequency shaking, each station is equipped with three sensors. GPS sensors measure long-term

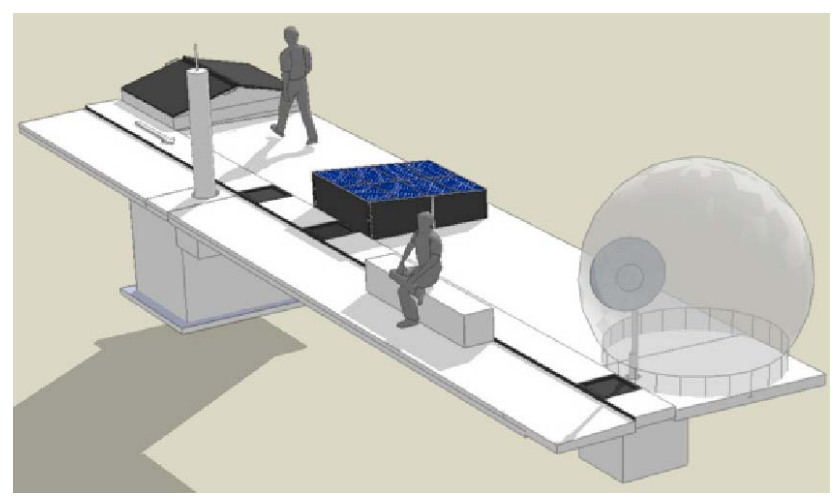

Figure 2. Perspective view of a VSAT station with, from top to bottom; the seismic vault, the GPS monument, the solar power station and the VSAT antenna under a radome (by courtesy of Atelier David Besson-Girard Paysagiste, Paris).

displacement; broadband seismometers (from $50 \mathrm{~Hz}$ up to 120 s or 240 s in the flat band) record earthquakes from magnitude 3 and force feedback, $\pm 2 \mathrm{G}$ accelerometers record, without being saturated, strong earthquakes, including any that might occur close to the station. Stations are deployed in quiet environment as far from anthropogenic noise as possible.

The solar system that powers the station is designed to provide 60 Watts continuously for at least 10 days without sunlight. This robust solar system is comprised of two distinct sub-systems, each with the capacity to deliver a minimum power of 30 Watts in case one element fails. Four stations have their VSAT antenna protected with a radome, which can withstand hurricane winds up to $300 \mathrm{kph}$, thus maintaining a minimal network with location capability for moderate to large magnitude earthquakes, under such conditions. The geodetic GPS antenna is located on top of a two-meter pedestal with a 1 cubic meter concrete foundation to promote long-term stability. Care has been taken in the design of the top of the pedestal in order to remove multi-path reflections by employing a dome shape. The geodetic sensor at some stations is shared with the COCONet network (UNAVCO project, EAR-1042906/9, http://coconet.unavco.org/coconet. $\mathrm{html}$ ) and those were installed by UNAVCO in accordance with their standards. Both seismometer and accelerometer are installed in a $2 \mathrm{~m}$ deep vault, on a common seismic pier. One station is installed in a $4 \mathrm{~m}$ borehole drilled in hard rock.

\section{Vault design}

The vault design (Fig. 3) addresses several needs: cost, environmental insulation, ground coupling, instrument security, available land (Saurel et al., 2012). A drain pipe was installed in each vault to reduce the risk of the vault being flooded. Vaults have been installed, insofar as possible, at the opposing side of the site from the VSAT antennae, in order to min- 


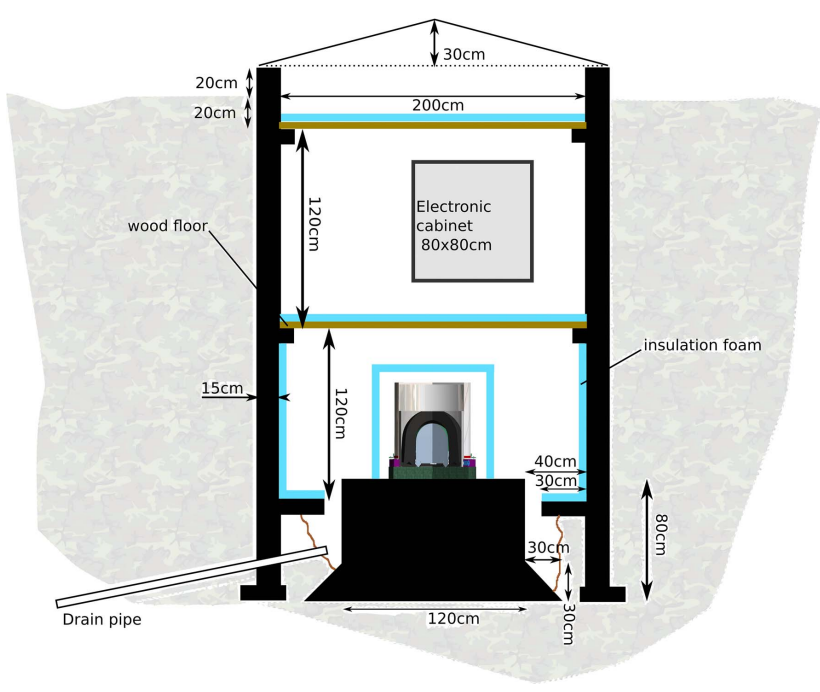

Figure 3. Seismic vault cross section, dimensions are in centimeters. The solid black represents the concrete structure, the solid blue parts are insulation foam and the brown lines represents the wooden floors.

imize any transmission of vibrations from the antennae mast to the instruments. The seismic pier, which can accommodate a broadband seismometer, with its insulation, and an accelerometer, is mechanically isolated from the vault walls. Thermal insulation and ground coupling are both achieved by excavating $2 \mathrm{~m}$ of soil. When possible, the seismic pier is directly grouted on to the rock basement. When rock was not available, one cubic meter of concrete was poured before the seismic pier was erected. The sensors are separated from the electronics in order to avoid any electric, magnetic and thermal mutual influence. This also allows maintenance of the electronics with minimal disturbance to the sensors' thermal environment. The vault is further insulated with $6 \mathrm{~cm}$ thick Styrofoam panels covering every floor. Additionally a box, in the same material, covers the seismic sensor.

\section{CASSIS shielding}

Changes in barometric pressure contribute significantly to seismometer noise level (Zürn and Widmer-Schnidrig, 1995; Beauduin et al., 1996). While there is little to be done to compensate for the local Earth induced tilt, the buoyancy effect on seismometer masses can be attenuated by proper shielding. The original Stuttgart shielding (Widmer-Schnidrig and Kurrle, 2006) has been proven to decrease the vertical noise level of broadband sensors by several dBs, without degrading performance of the horizontal axes. IPGP engineers from Geoscope (Stutzmann et al., 2000) and the volcanic observatory team added some innovative features to this initial design. This is the CASSIS shielding (CASserole SISmologique - seismic cooking pot) which is still based on the granite slab and "cooking pot" pair (Fig. 4). The granite base

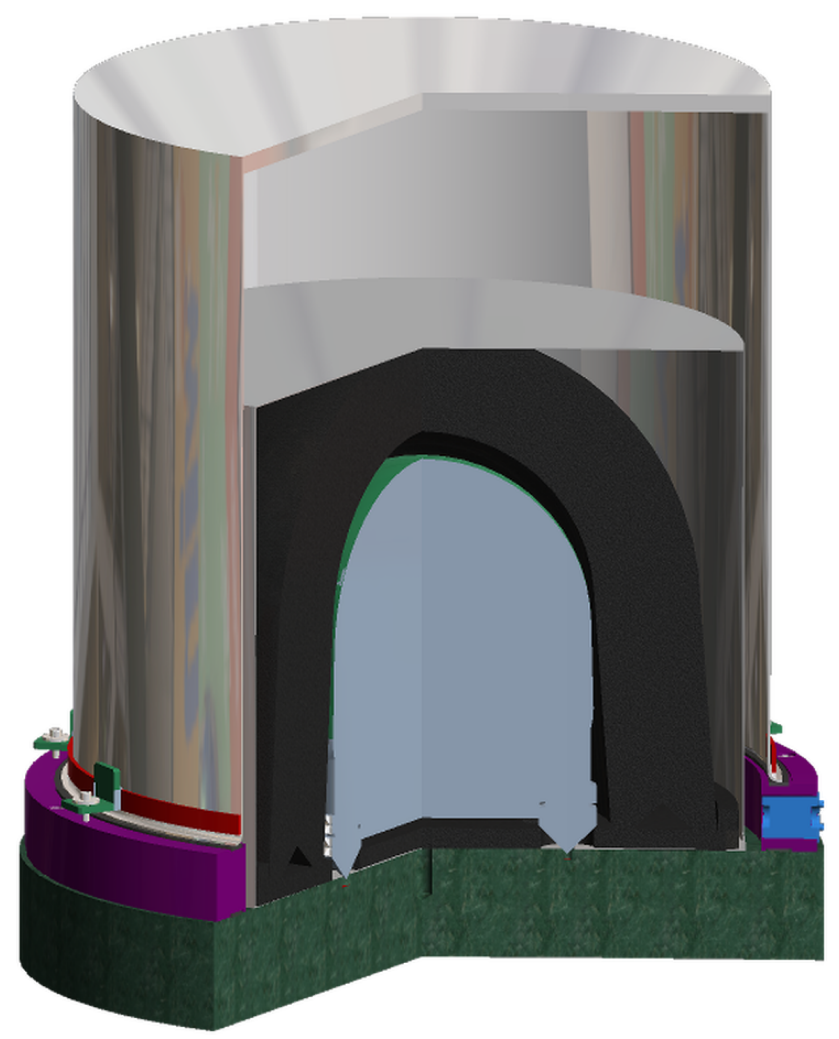

Figure 4. CASSIS seismometer insulation with, from the inside to the outside; the Trillium seismometer, the foam cover, the mu-metal cover, the stainless steel cover bolted to the granite base plate. The cable goes out through the blue joint on the right hand side of the schematic.

plate is engraved with a North-South indication, along with the positions for three different sensors: Streckeisen STS2 family, Nanometrics Trillium120PA and Nanometrics Trillium240. The design may be adjusted to host other seismometers once their footprint is known. A metal ring (either aluminium or stainless steel), with a neoprene gasket, is bolted to the granite plate. This allows the use of the original sensor cables through a hole, which is sealed afterwards with a compressed rubber gasket. This decreases the number of connectors on the electrical signal path, which enhances performance and is always a good measure for long-term installations. A foam cover fits the sensor and provides thermal insulation via a thin air gap that also suppresses thermal convection currents around the sensor. Finally, a stainless steel "cooking pot" is bolted and sealed to the metal ring, providing proper barometric pressure shielding. This barometric shielding is now in use in the Geoscope network and replaces the original Stuttgart design.

Extensive tests were conducted on this shielding in Martinique Geoscope vault (FDF station), which hosts an STS2 shielded with the original Stuttgart design. The Trillium120PA and Trillium240 sensors were tested. It was 

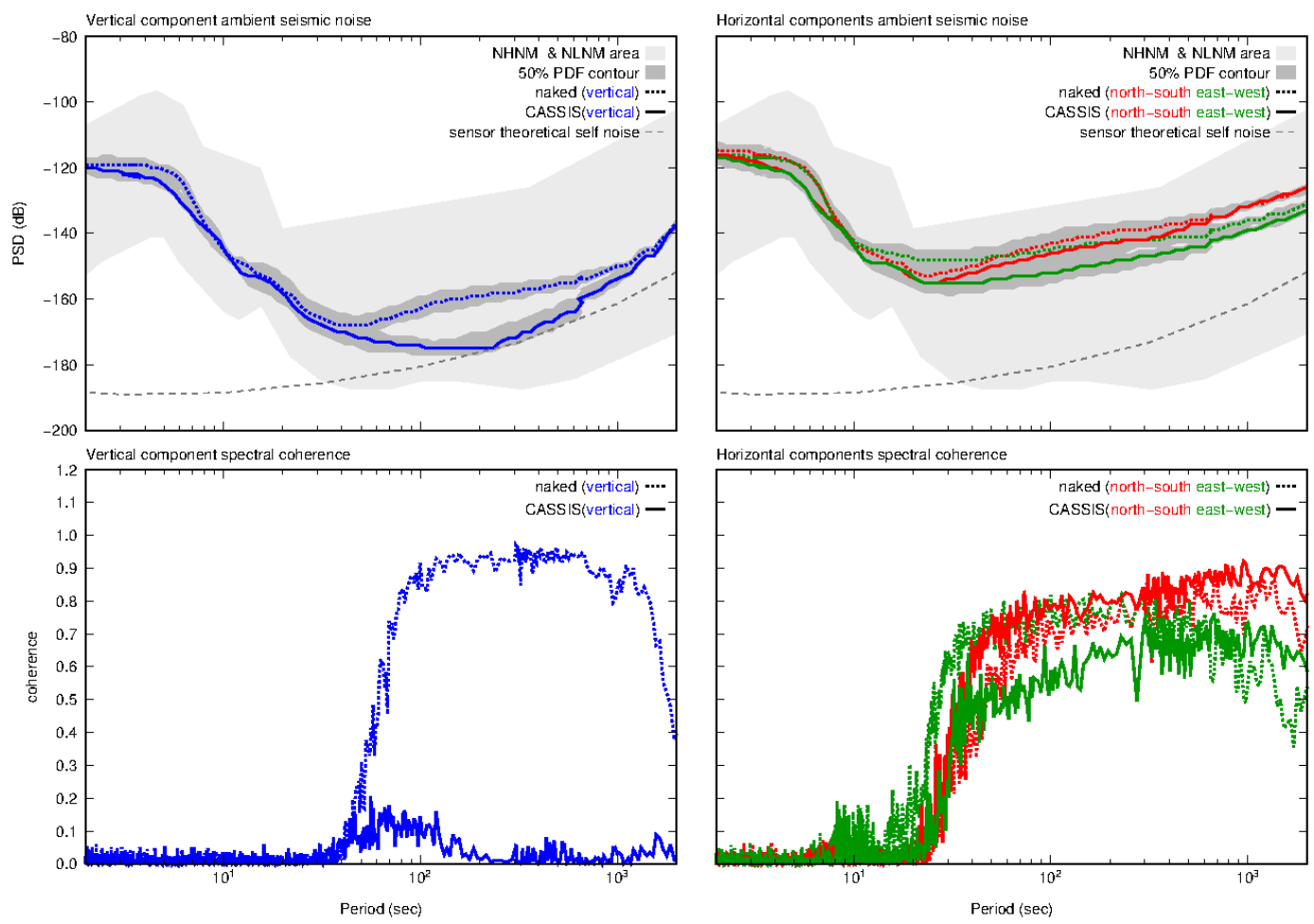

Figure 5. Influence of the CASSIS barometric shielding on Trillium120PA noise level. CASIS has a significant impact on the vertical component noise level (blue). The spectral coherence plots confirms the barometric pressure origin of the noise. Top-left figure compares vertical noise level of the shielded (solid lines) and naked (dotted lines) seismometers, with the 50\% PDF contour (dark shaded area). Idem for horizontal components in top-right figure. Bottom-left figure compares vertical spectral coherence between velocity and barometric pressure of the shielded (solid lines) and naked (dotted lines) seismometers. Idem for horizontal components in bottom-right figure. Barometric and seismic signals were down-sampled to $1 \mathrm{sps}$, and high pass filtered at $0,2 \mathrm{mHz}$ before the spectral coherence computation. Ambient noise plots combines raw 1 and 20 sps data. Thick dotted gray line represents the theoretical self noise level of the seismometer, according to Nanometrics (P. Devanney, personal communication, 2012) and the light shaded area the NHNM and NLNM boundaries (Peterson, 1993).

found that the barometric shielding for the Trillium240 did not yield significant changes in noise levels. It is considered that a very rigid sensor housing may reduce sensitivity to barometric pressure, which would explain the results obtained on this sensor. The shielding did not alter instrument performance, which was maintained on all axes. The noise level on the Trillium120PA was improved by the CASSIS shielding, up to $10 \mathrm{dBs}$ in the 100s range (Fig. 5, upper plots). We calculated spectral coherence between the seismic sensor signals converted to velocity and barometric pressure as recorded by the Geoscope microbarometer (Fig. 5, bottom plots). The results clearly show that, within the 40s to 1000 s range, the coherence between the Trillium120PA signals and the barometric pressure is very high for all the axes. When installing the sensor under the CASSIS shielding, the same plot shows almost no coherence in that same period range for the vertical component. The remaining coherence on the horizontal component might be due to tilt and not to a direct pressure effect on the masses. Those results are consistent with the TANK shielding used in Observatoire de Grenoble
(OSUG) seismic network, which was inspired by CASSIS design (Langlais et al., 2013).

Finally, efforts were made to reduce another type of external influence, observed in 2007 at BFO (Black Forest Observatory) (Forbriger, 2007; Forbriger et al., 2010) on very broadband sensors, including an early design of Trillium 240 . Wielandt (2007) stated in a Nanometrics Trillium240 test report, conducted in 2007 , that this new sensor was more sensitive to terrestrial magnetic fields than the reference STS2. But when removing this influence using active coils around the seismometer, he was able to demonstrate a noise level at least on a par with that of the STS2. Therefore, a mumetal cover was designed to damp magnetic field variations by $100 \mathrm{~dB}$ between $50 \mathrm{~s}$ and $600 \mathrm{~s}$, which is the range of the strongest natural variations during magnetic storms. During the tests, significant solar eruptions occurred that generated perturbations of the Earth magnetic field (Kp index of 80 for the whole day). The records from the closest Intermagnet station in Puerto Rico were compared with the signals recorded by the three very broadband sensors in use on the Geoscope pier at the time : the reference Geoscope STS2, 


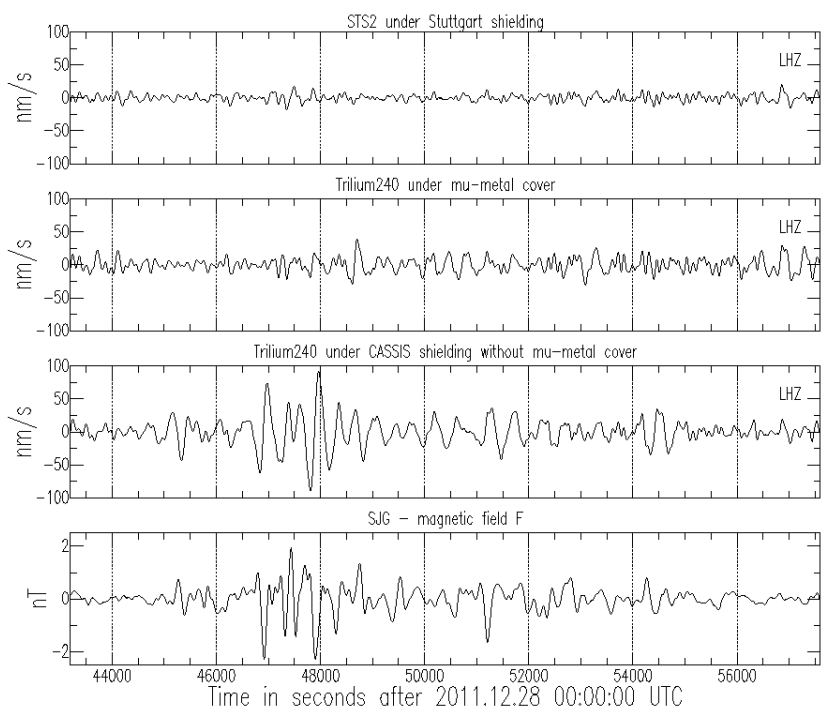

Figure 6. From top to bottom, Geoscope STS2 with Stuttgart shielding which has a low sensitivity to magnetic fields, Trillium 240 with mu-metal cover which proves to reduce the magnetic field influence, Trillium240 with CASSIS shielding without mu-metal cover showing the influence of Earth magnetic field and San Juan (Puerto Rico) filtered value of Earth magnetic field. All signals were filtered between 1 and $10 \mathrm{mHz}$, and seismic recording were deconvolved to velocity.

a Trillium240 under the CASSIS shielding only and a Trillium240 under the mu-metal cover only. Figure 6 shows a 4hour record of the four signals. Because the closest magnetic field record we could use is from San Juan (Puerto Rico) station, it may include some local effects, either due to a different geology or local sources. Similarly, local disturbances in Martinique might have produced some effects on the seismometer records. This explains why some parts of the magnetic signal differ with those on the seismic signal. Vertical seismic components are deconvolved to velocity. All signals are filtered between 100s and 1000s. We can clearly see the impact of the mu-metal cover: near complete removal of the magnetic influence on the Trillium240 was achieved. As a result, this shielding has been installed on all Trillium240 sensors in the network.

\section{Network performance}

These measures have led to a good level of performance across the network, homogeneous at the arc scale. Figure 7 shows the noise performance of 6 Trillium 240 and 6 Trillium120PA stations installed in Guadeloupe, Martinique, Carriacou, Dominica, Antigua and Saint-Lucia, during November 2014. The stations PSDs were calculated and merged with PQLX software (McNamara and Boaz, 2005). Then, PDFs median noise and their 50, 80 and $90 \%$ contours were calculated. Despite very different siting condi- tions (rock, clay, natural soil, volcanic deposits), the vertical PDF median noise level above 10s is close to the NLNM (New Low Noise Model, Peterson, 1993). It is also important to highlight that the stations are installed on islands and are never more than $50 \mathrm{~km}$ from the shore and the breaking waves of the Atlantic Ocean. The small 50 and $80 \%$ contours, for most of the period range, show that the care taken in station site selection, vault infrastructure and sensor shielding design insulate the sensors from environmental influences and was, therefore, worthwhile. The Trillium120PA plot, shows a similar noise curve to that of the test in Fig. 5, and demonstrates that the CASSIS shielding works as expected in the field . At shortest periods, the difference between the stations is more apparent with larger PDF contours. This is normal since high frequency noise is mainly caused by local sources and thus more site specific. Lastly, both Trillium120PA and Trillium240 subsets of stations show an overall PDF median noise close to their respective sensor theoretical self noise level.

\section{Conclusions}

This redundant and robust regional network now allows homogeneous earthquake location in the region and a minimal level of monitoring and early warning in the event of major natural events without relying on terrestrial data transmission links. The completion of this network makes high quality broadband seismic data from the Lesser Antilles subduction zone available. It should lead to improved understanding of the tectonic processes at work in this region and allow for improved hazard assessments. This network meets its main three objectives, allowing accurate location of earthquakes in this zone, providing real-time data for the CARIBE-EWS with a high level of availability and offering quality data sets for researchers to understand Lesser Antilles subduction. This network deployment shows how important it is to invest in station infrastructures to achieve high quality data and a reliable and resilient network.

Acknowledgements. We would like to thank everyone, from Trinidad and Tobago, Paris, Martinique and Guadeloupe, involved in the different projects, spanning many years, that led to the completion of our network. In particular: SRC team, who pioneered the installation of VSAT broadband stations in the region, board of direction of IPGP and Sara Bazin, who fully supported the Lesser Antilles network project, Christian Anténor-Habazac and his colleagues from Guadeloupe observatory who installed the first VSAT station in a French territory, Tanguy Maury and his colleagues from Martinique observatory for their efforts during the VSAT station installations in Martinique. We are also grateful to all the funding French agencies without which this project would not have been possible: VSAT stations in Martinique (2), Saint Lucia (1), Carriacou (1), Dominica (1), Antigua (1) were co-fund by the European INTERREG Tsuareg project, lead in Martinique. The hub of Martinique was fund by the Research Ministry, VSAT stations 

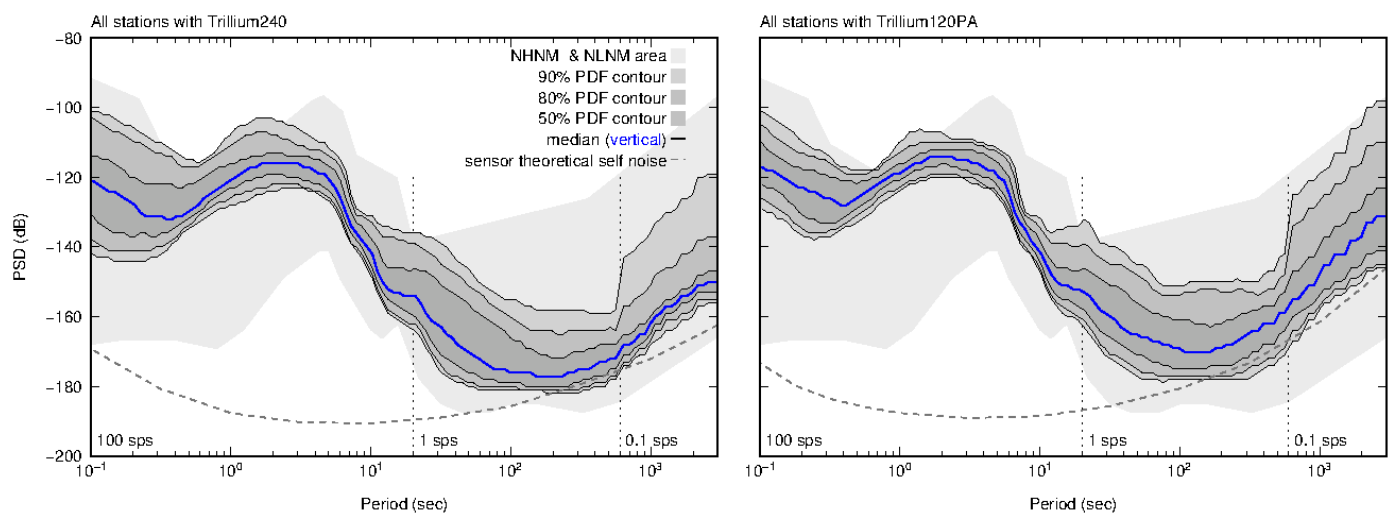

Figure 7. PDF plots of 6 Trillium 240 and 6 Trillium120PA stations in the Lesser Antilles during the same time period (from the 27 October to the 26 November), showing the PDF median line, 90, 80 and 50\% PDF contours for the vertical ambient noise. CASSIS shielding improvement, as shown in Fig. 5, can be seen on the whole network, for both seismometers. Thick dotted gray line represents the theoretical self noise levels of the seismometer, according to Nanometrics (P. Devanney, personal communication, 2012). The light shaded area represents the NHNM and NLNM boundaries (Peterson, 1993). At long periods, the contours are affected by the small number of time windows used for the PDF estimation, reducing the precision of the PSD. Vertical dashed lines highlight the three sample rates used for PSD computation in three period domains. Despites varied local conditions, we can note how close the median noise and its lower contours are to the sensor theoretical self noise between 30s and 1000s. There is more variations at short periods, as the noise is mainly affected by local sources (wind, breaking waves, human activities) which are hardly attenuated by any insulation.

in Martinique (2) by the French Environment Ministry, the VSAT stations and the hub of Guadeloupe (7) by CPER PO Guadeloupe funds, co-funded by the French Ministry of Research, the French Ministry of Environment, the Guadeloupe Regional Council and IPGP. We thank all the local communities and authorities for their support, the private owners or the local authorities that made land available for the station installation in their territories. The results presented in this paper rely on the data collected at the San Juan geomagnetic observatory, Puerto Rico. We thank USGS, for supporting its operation and INTERMAGNET (Kerridge, 2001) for promoting high standards of magnetic observatory practice (www.intermagnet.org).

Edited by: Damiano Pesaresi

Reviewed by: two anonymous referees

\section{References}

Beauduin, R., Lognonné, P., Montagner, J. P., Cacho, S., Karczewski, J. F., and Morand, M.: The effects of atmospheric pressure changes on seismic signals or how to improve the quality of a station, B. Seismol. Soc. Am., 86, 1760-1769, 1996.

Bernard, P. and Lambert, J.: Subduction and seismic hazard in the northern Lesser Antilles: Revision of the historical seismicity, B. Seismol. Soc. Am., 78, 1965-1983, 1988.

Feuillet, N., Beauducel, F., and Tapponnier, P.: Tectonic context of moderate to large historical earthquakes in the Lesser Antilles and mechanical coupling with volcanoes, J. Geophys. Res., 116, B10308, doi:10.1029/2011JB008443, 2011.

Forbriger, T.: Reducing magnetic field induced noise in broad-band seismic recordings, Geophys. J. Int. 169, 240-258, 2007.

Forbriger, T., Widmer-Schnidrig, R., Wielandt, E., Hayman, M., and Ackerley, N.: Magnetic field background variations can limit the resolution of seismic broad-band sensors, Geophys. J. Int., 183, 303-312, 2010.

Forbriger, T.: Recommendations for seismometer deployment and shielding. Information Sheet IS 5,4, in: New Manual of Seismological Observatory Pratice (NMSOP-2), edited by: Bormann, P., 2nd Edn., IASPEI, GFZ german Research Center for Geoscience, Potsdam, 2012.

Hough, S. E.: Missing great earthquake, J. Geophys. Res., 118, 1098-1108, 2013.

Kerridge, D.: INTERMAGNET: WorldWide Near-Real-Time Geomagnetic Observatory Data, available at: http://www. intermagnet.org/index-eng.php, 2001.

Lander, F., Whiteside, L. S., and Lockridge, P. A.: Caribbean tsunami, an Initial History, Natural Hazards and Hazards Management in the Greater Caribbean and Latin America, 3, 1-18, 1997.

Langlais, M., Vial, B., and Coutant, O.: Improvement of broadband seismic station installations at the Observatoire de Grenoble (OSUG) seismic network, Adv. Geosci., 34, 9-14, doi:10.5194/adgeo-34-9-2013, 2013.

McNamara, D. E. and Boaz, R. I.: Seismic Noise Analysis System Using Power Spectral Density Probability Density Fonctions: A Stand-Alone Software Package, USGS Open-File Report 20051438, 2005.

Mori, N., Takahashi, T., Yasuda, T., and Yanagisawa, H.: Survey of 2011 Tohoku earthquake tsunami inundation and run-up, Geophys. Res. Lett., 38, L00G14, doi:10.1029/2011GL049210, 2011.

Peterson, J.: Observations and Modeling of Seismic Background Noise, USGS, Open-File Report 93-322, 1993.

Sakic, P.: Spéfications de monumentation utilisés dans le cadre du projet GPSJURA, Observatoire des sciences de l'univers de Besançon, Réseau national GPS (RENAG), 2013. 
Saurel, J.-M., Anglade, A., Maury, T., Lemarchand, A., Lynch, L., Higgins, M., Clouard, V., Bouin, M.-P., Robertson, R., de Chabalier, J.-B., Tait, S., Nercessian, A., and Latchamn, J. L.: Ecar virtual broadband seismic network: vault construction techniques and seismometer insulation, Caribbean Wave II conference, 2012.

Shepherd, J. B.: Comment on "Subduction and seismic hazard in the Lesser Antilles" by Pascal Bernard and Jérôme Lambert, B. Seismol. Soc. Am., 82, 1534-1543, 1992.

Singh, S. C., Hananto, N., Mukti, M., Robinson, D. P. , Das, S., Chauhan, A., Carton, H., Gratacos, B., Midnet, S., Djajadihardja, Y., and Harjono, H.: Aseismic zone and earthquake segmentation associated with a deepsubducted seamount in Sumatra, Nat. Geosci., 4, 308-311, doi:10.1038/NGEO1119, 2011.

Stutzmann, E., Roult, G., and Astiz, L.: Geoscope Station Noise Levels, B. Seismol. Soc. Am., 90, 690-701, 2000.
Trnkoczy, A., Bormann, P., Hanka, W., Holcomb, L. G., Nigbor, R. L., Shinaohara, M., Shiobara, H., and Suyehiro, K.: Chapter 7, Site Selection, Preparation and Installation of Seismic Stations, in: New Manual of Seismological Observatory Pratice (NMSOP2), edited by: Bormann, P., 2nd Edn., IASPEI, GFZ german Research Center for Geoscience, Potsdam, 2011.

UNAVCO Resources: GNSS Station Monumentation, available at: http://facility.unavco.org/kb/questions/104, 2010.

Widmer-Schnidrig, R. and Kurrle, D.: Evaluation of Installation Methods for Streckeisen STS-2 Seismometers, Deutschen Geophysikalischen Gesellschaft (DGG), 2006.

Wielandt, E.: Two tests of the Trillium240 very-broad-band seismometer, personal report, November 2007.

Zürn, W. and Widmer-Schnidrig, R.: On noise reduction in vertical seismic records below $2 \mathrm{mHz}$ using local barometric pressure, Geophys. Res. Lett, 22, 3537-3540, 1995. 